Wresni Anggraini, Anifah Naswan Ilhamda Putri

\title{
Perbaikan Efisiensi Jalur Layanan Pasien Rumah Sakit dengan Menggunakan Pendekatan Lean Healthcare
}

\author{
Wresni Anggraini \\ UIN Sultan Syarif Kasim Riau \\ Anifah Naswan Ilhamda Putri \\ UIN Sultan Syarif Kasim Riau \\ wresni_anggraini@ymail.com
}

\begin{abstract}
Abstrak
Standar pelayanan minimal rumah sakit tentang waktu tunggu untuk rawat jalan yang ditetapkan oleh Kemenkes Nomor. 129/Menkes/SK/II/2008 adalah tidak lebih dari 60 menit. Masalah yang dihadapi oleh Poli Tulip Rumah Sakit X Pekanbaru adalah waktu menunggu pasien lebih dari 60 menit. Tujuan dari penelitian ini adalah memberikan usulan perbaikan untuk mengurangi waktu tunggu pasien.. Metode yang digunakan pada penelitian ini adalah lean healthcare menggunakan analisis Value Stream Mapping (VSM) untuk menentukan nilai Process Cycle Efficiency (PCE). Berdasarkan current state value stream mapping nilai PCE saat ini adalah 16,85\%, ini berarti efisiensi lini pada Poli Tulip Rumah Sakit X Pekanbaru masih sangat rendah. Proses usulan perbaikan efisiensi lini dengan cara mengidentifikasi dan mengurangi non value added activity dan waste yang paling sering terjadi pada proses pelayanan pasien. Ditemukan waste yang berpengaruh menyebabkan waste delay adalah waste unnecessary movement dan lost oppurtunity to retain or win customers yaitu sebesar 22,11\%. Untuk mencari akar penyebab waste dilakukan root cause analysis. Akar penyebab masalah dari waste yang terjadi di lini pelayanan pasien bersumber dari faktor individual pegawai dan manajerial Rumah Sakit. Simulasi future state value stream mapping dengan menggunakan ARENA dilakukan untuk menguji usulan perbaikan, didapatkan nilai PCE harapan sebesar 36,18\%, yang berarti dengan usulan perbaikan yang diberikan telah meningkatkan efisiensi jalur layanan pasien di Poli Tulip sebesar 19,33\%.
\end{abstract}

Kata Kunci : Lean Healthcare, Waste, Root Cause Analysis, Value Stream Mapping, Process Cycle Efficiency

\section{Pendahuluan}

Rumah Sakit X Pekanbaru merupakan salah satu sarana kesehatan yang menyelenggarakan pelayanan kesehatan perorangan meliputi pelayanan promotif, preventif, kuratif dan rehabilitatif yang menyediakan pelayanan rawat inap, rawat jalan dan gawat darurat. Jumlah pasien rawat inap tahun 2016-2018 adalah 32.339 orang dan jumlah pasien rawat jalan tahun 2016-2018 adalah 145.999 orang. Instalasi rawat jalan memiliki 4 poliklinik dengan persentase jumlah pasien pada tahun 2018 adalah Poli Anggrek 17,75\%, Poli Bugenvil 19,85\%, Poli Edelweiss 22,50\% dan Poli Tulip 39,90\%. Instalasi rawat jalan BPJS Poli Tulip memiliki jumlah pengunjung paling banyak sehingga sering terjadi antrian panjang pasien dan menyebabkan lamanya waktu tunggu pasien untuk dilayani. Alur proses pelayanan pasien rawat jalan BPJS poli tulip dapat dilihat pada gambar 1 Current State Value Stream Mapping (Current VSM). 


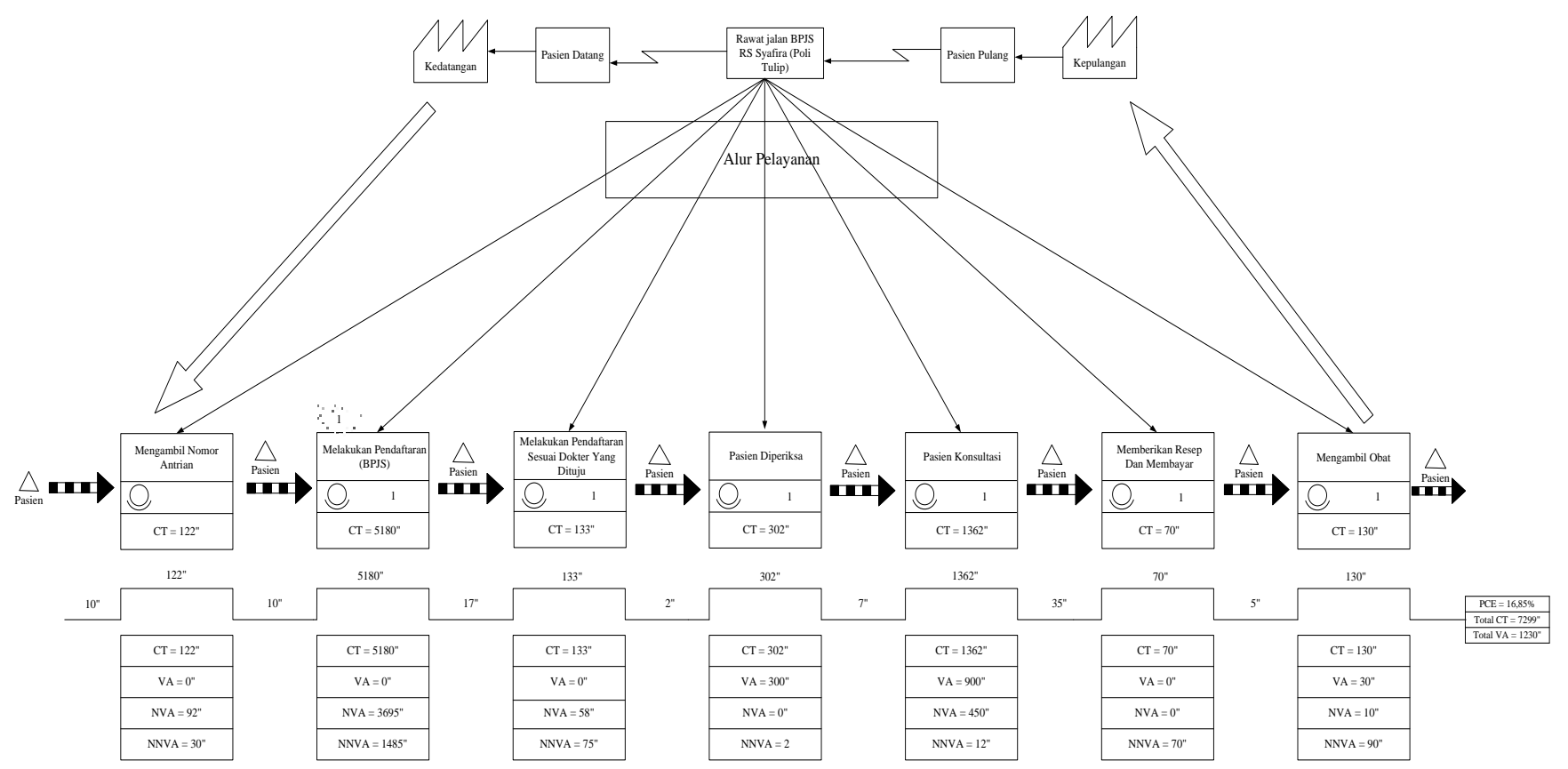

Gambar 1. Current State Value Stream Mapping Proses Pelayanan Rawat Jalan BPJS Poli Tulip

Berdasarkan current VSM, diketahui nilai Process Cycle Efficiency (PCE) pada lini pelayanan Poli Tulip adalah sebesar $16,85 \%$, telah terjadi beberapa pemborosan pada lini pelayanan seperti dirangkum pada table 1 . Pemborosan yang terjadi menyebabkan lamanya waktu tunggu pasien dalam pendaftaran, mendapatkan pelayanan dokter dan layanan pengambilan obat.

\section{Tabel 1. Pemborosan/Waste yang Terjadi di Lini Pelayanan Poli Tulip Rumah Sakit X}

\begin{tabular}{|c|c|}
\hline Waste & Aktifitas yang termasuk pemborosan \\
\hline \multirow{2}{*}{ Duplication } & 1.Pendaftaran ulang karena pelaksanaan pendaftaran gagal \\
\hline & 2.Mengulangi tes karena tidak tersedianya informasi yang benar \\
\hline \multirow{3}{*}{ Delay } & 1. Menunggu pendaftaran BPJS dan verifikasi kelengkapan data pada poliklinik \\
\hline & 2. Menunggu antrian pengambilan obat \\
\hline & 3. Menunggu pemeriksaan dan konsultasi \\
\hline $\begin{array}{l}\text { Unnecessary } \\
\text { movement }\end{array}$ & $\begin{array}{l}\text { Petugas administrasi BPJS duduk berdiri berulang kali, pegawai administrasi } \\
\text { berjalan mengambil berkas, petugas berjalan menggambil kertas surat eligibilitas } \\
\text { pasien. }\end{array}$ \\
\hline \multirow{2}{*}{$\begin{array}{l}\text { Unclear } \\
\text { communication }\end{array}$} & $\begin{array}{l}\text { 1. Petugas pengambilan obat menyampaikan informasi yang tidak jelas dengan } \\
\text { pasien terkait informasi obat yang diberikan }\end{array}$ \\
\hline & 2. Pasien tidak menceritakan seluruh penyebab timbulnya sakit \\
\hline $\begin{array}{l}\text { Lost opportunity to } \\
\text { retain or win } \\
\text { customers }\end{array}$ & $\begin{array}{l}\text { Perawat tidak ramah dengan pasien, petugas membedakan golongan pasien dan } \\
\text { membedakan fasilitas. }\end{array}$ \\
\hline Incorrect inventory & $\begin{array}{l}\text { Pasien yang dilayani melebihi dari kesanggupan SDM dan jam buka pengambilan } \\
\text { nomor antrian melebihi waktu yang sudah ditetapkan }\end{array}$ \\
\hline
\end{tabular}


Tujuan dari penelitian ini adalah :

1. Mengidentifikasi non value added activity yang menjadi waste pada proses pelayanan instalasi rawat jalan di Poli Tulip Rumah Sakit X Pekanbaru.

2. Mencari akar penyebab masalah dari waste yang terjadi di lini pelayanan Poli Tulip Rumah Sakit X Pekanbaru.

3. Membuat usulan perbaikan pelayanan untuk mengurangi waktu tunggu pelayanan pasien dengan cara meningkatkan Process Cycle Efficiency pada lini layanan Poli Tulip

\section{Landasan Teori}

Pendekatan Lean merupakan suatu upaya terus-menerus untuk menghilangkan waste (pemborosan) dan meningkatkan value added (nilai tambah) produk barang maupun jasa agar memberikan customer value. Tujuan lean adalah untuk meningkatkan customer value melalui peningkatan terus menerus rasio antara nilai tambah terhadap waste (Gaspers.V \& Fontana.A. 2011). Lean sebagai suatu filosofi bisnis yang berlandaskan pada minimasi penggunaan sumber-sumber daya (termasuk waktu) dalam berbagai aktivitas perusahaan. Lean berfokus pada identifikasi dan eliminasi aktivitas-aktivitas yang tidak bernilai tambah (non value added activities) dalam desain dan produksi (untuk bidang manufaktur) atau operasi (untuk bidang jasa) dan supply chain management yang berkaitan langsung dengan pelanggan. Lean bertujuan untuk meningkatkan secara terus-menerus customer value melalui peningkatan terusmenerus rasio antara nilai tambah terhadap waste (the value to waste ratio). Suatu perusahaan dapat dianggap lean apabila rasio antara nilai tambah terhadap waste mencapai minimum $30 \%$. (Anggraini, W, 2020)

Tools yang dapat digunakan untuk pendekatan lean adalah value stream mapping (VSM), waste relationship matrix (WRM), root cause analysis (RCA). VSM merupakan salah satu alat metode Lean yang paling sering digunakan dalam organisasi kesehatan untuk menganalisa keadaan saat ini atau mengidentifikasi area yang bermasalah dan menciptakan desain solusi untuk masalah yang terjadi (R. F. Syahri et al, 2017.) Tools waste relationship matrix merupakan suatu matrix yang digunakan untuk menganalisa kriteria pengukuran, matrix yang terdiri dari baris dan kolom, baris menunjukkan pengaruh suatu waste tertentu terhadap ke 6 waste lainnya, sedangkan setiap kolom menunjukkan waste yang dipengaruhi oleh waste lainnya. Hasil keterhubungan itulah yang nantinya dicari penyebab masalahnya dengan root cause analysis (Rawabdeh, 2005).

Lean Hospital adalah suatu aturan yang merupakan suatu sistem manajemen dan juga suatu filosofi yang dapat merubah cara pandang suatu rumah sakit agar lebih teratur dan teroganisir dengan memperbaiki kualitas layanan untuk pasien dengan cara mengurangi kesalahan dan mengurangi waktu tunggu (Graban, 2009). Metode Lean yang digunakan rumah sakit untuk memperbaiki kualitas layanan terhadap pasien dengan mengurangi dua permasalahan utama yaitu mengurangi kesalahan (reducing errors) dan waktu tunggu (waiting time). Lean Hospital dibutuhkan agar Rumah Sakit dapat memenuhi kebutuhan pasien secara optimal, dapat memberikan pelayanan kesehatan semaksimal mungkin kepada pasien dengan mengurangi waste (pemborosan) yang pada akhirnya akan menciptakan nilai tambah bagi Rumah Sakit. Metode lean yang digunakan rumah sakit untuk memperbaiki kualitas layanan terhadap pasien dengan mengurangi dua permasalahan utama yaitu mengurangi kesalahan (reducing errors) dan waktu tunggu (waiting time). Graban mendefinisikan lean menjadi dua hal, yaitu: 
a. Total Elimination Waste. Pemborosan, muda, atau waste merupakan segala aktivitas yang tidak mencerminkan bantuan dalam proses penyembuhan terhadap pasien. Semua pemborosan harus dihilangkan atau minimal dikurangi agar dapat menekan biaya rumah sakit, meningkatkan kepuasan pasien, serta meningkatkan keselamatan pasien dan pegawai. Contoh waste yang ada dirumah sakit adalah: Waktu tunggu pasien untuk diperiksa oleh dokter, Waktu tunggu untuk proses berikutnya, Adanya kesalahan yang membahayakan pasien dan Pergerakan yang tidak perlu, misal letak apotik dan kasir yang terlalu jauh.

b. Respect for People. Respect dalam konteks lean memiliki sejumlah cara untuk mendorong karyawan agar termotivasi untuk melakukan pekerjaan yang lebih baik dengan cara konstruktif dengan cara melakukan respect kepada pasien, karyawa, dokter, dan semua stakeholder yang terdapat dalam rumah sakit beserta lingkungannya.

Penelitian yang dilakukan Setyaningsih merupakan penelitian terhadap kepuasan pelanggan terhadap proses pelayanan menggunakan konsep lean serverf, keterkaitan dengan penelitian yang dilakukan adalah bagaimana memperbaiki atribut yang terdapat permasalahan. Kekurangan dari penelitian berfokus pada pasien dan tidak mempertimbangkan akar penyebab permasalahan dari pihak rumah sakit (Setyaningsih, 2013).

Penelitian yang dilakukan Kovacevic M, tentang Lean Thinking Healthcare menyatakan sebagai hasil utama, penerapan konsep lean dipastikan kepada organisasi perawatan kesehatan untuk fokus pada inti utama mereka berfungsi dan mendedikasikan lebih banyak waktu dan upaya untuk pasien tanpa biaya tambahan untuk mereka atau sistem perawatan kesehatan. Namun, ramping implementasi dalam perawatan kesehatan bisa jadi jauh lebih sulit daripada di lingkungan industri standar dan ada sejumlah besar contoh lean dalam proyek perawatan kesehatan yang gagal mendapatkan hasil yang terukur dan berkelanjutan manfaat darinya (Kovacevic M, 2016).

Penelitian Ahmad H.S, tentang Implementation of lean management to reduce waiting time for drugs in Islamic Hospital, menganalisis waktu tunggu berdasarkan proses, menunjukkan kondisi yang identik dengan jumlah subproses di rantai layanan. Rata-rata terpanjang waktu tunggu adalah pelayanan kepada debitur asuransi, diikuti oleh BPJS dan uang tunai. Studi ini menunjukkan bahwa Penerapan manajemen lean dapat mengurangi lamanya waktu tunggu pelayanan apotek diunit rawat jalan dari Peracikan obat maupun obat non racikan (Ahmad H.S, 2020)

\section{Metode Penelitian}

\section{a. Value Stream Mapping}

Value stream didefinisikan sebagai himpunan semua tindakan khusus yang diperlukan untuk membawa produk tertentu melalui tiga kritis tugas manajemen bisnis apapun yaitu problem solving, manajemen informasi dan transformasi fisik. Value stream juga didefinisikan sebagai sekumpulan dari seluruh kegiatan yang didalamnya terdapat kegiatan yang memberikan nilai tambah (value added) dan juga yang tidak memberikan nilai tambah (non value added) yang dibutuhkan untuk membawa produk maupun satu grup produk dari sumber yang sama untuk melewati aliran-aliran utama, mulai dari raw material hingga sampai ke tangan konsumen (Gaspersz, 2006). Tiga jenis aktivitas dalam value stream mapping adalah sebagai berikut: 
Wresni Anggraini, Anifah Naswan Ilhamda Putri

1. Nilai menambah kegiatan (Value Added)

Kegiatan itu di mata pelanggan membuat produk atau layanan yang lebih beharga.

2. Non Nilai tambah kegiatan (Non Value Added)

Kegiatan itu tidak membuat produk atau layanan yang lebih beharga yang tidak diperlukan.

3. Diperlupakan namun tidak mempunyai nilai tambah kegiatan (Necessary Non Value Added)

Kegiatan itu dimata pelanggan tidak membuat produk atau layanan yang lebih beharga tetapi diperlukan dalam alur proses.

\section{b. Process Cycle Efficiency (PCE)}

Berdasarkan current VSM, dihitung current PCE. PCE merupakan persentase dari waktu yang dipergunakan untuk menambah nilai pada produk dibandingkan total waktu yang dipergunakan produk selama dalam proses. Rumus perhitungan Process Cycle Efficiency (Anggraini W , 2020):

$$
\text { PCE }=\frac{\text { Total Value added time }}{\text { Total lead time }} \times 100 \%
$$

\section{c. Waste Relationship Matrix (WRM)}

Tahapan selanjutnya yang akan dilakukan yaitu menyebarkan kuesioner WRM kepada value stakeholders rawat jalan Poli Tulip yaitu terdiri dari petugas pendaftaran BPJS, petugas pendaftaran RS, perawat, dokter dan petugas farmasi. Simbol yang digunakan adalah simbol F melambangkan from, T melambangkan to, T melambangkan Unclear Communication, W melambangkan Delay, M melambangkan Unnecessary Movement, D melambangkan Duplication, O melambangkan Lost Oppurtinity To Retain or win Customers, I melambangkan Incorrect Inventory, serta PJ melambangkan pilihan jawaban.

WRM merupakan suatu matrix yang digunakan untuk menganalisa kriteria pengukuran. WRM merupakan matrix yang terdiri dari baris dan kolom. Setiap baris menunjukkan pengaruh suatu waste tertentu terhadap ke 6 waste lainnya. Sedangkan setiap kolom menunjukkan waste yang dipengaruhi oleh waste lainnya (Rochman, 2014).

Hubungan antar waste sangat kompleks karena pengaruh dari masing-masing jenis terhadap yang lainnya dapat tampak secara langsung atau secara tidak langsung. Untuk itu Rawabdeh (2005) mengembangkan suatu kerangka kerja penilaian tingkat pengaruh waste berdasarkan pengaruhnya terhadap waste lain. Petunjuk arah hubungan tujuh waste dapat dilihat pada Gambar 2. 


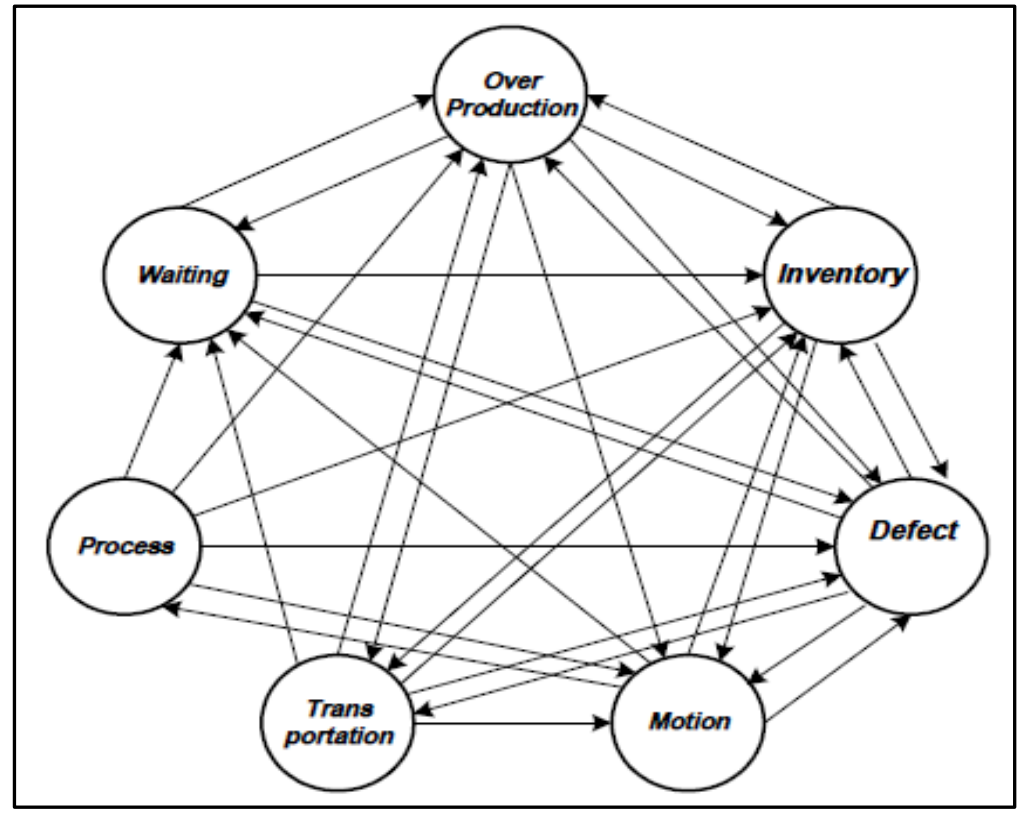

\section{Gambar 2 Hubungan Antar Waste (Sumber: Rawabdeh, 2005)}

\section{d. Root Cause Analysis}

Root Cause Analysis (RCA) adalah sebuah metode yang digunakan pada masalah yang akan dicari akar penyebabnya. RCA digunakan untuk memperbaiki atau mengeliminasi masalah dan mencegah masalah tersebut agar tidak muncul kembali. RCA adalah suatu proses yang dirancang untuk menginvestigasi dan mengkategorikan akar penyebab suatu peristiwa atau kejadian yang terjadi. RCA ini digunakan untuk mengidentifikasi kejadian yang menghasilkan atau memiliki potensi menghasilkan jenis-jenis konsekuensi (Rooney, 2014).

Root cause analysis digunakan setelah pemetaan terhadap aktivitas-aktivitas yang menimbulkan waste dan merupakan aktivitas-aktivitas non value added. Metode ini digunakan untuk mengetahui penyebab-penyebab apa sajakah yang menyebabkan terjadinya waste pada suatu aktivitas atau proses. Proses Root Cause Analysis harus dimulai pertama dengan membentuk tim yang terdiri dari anggota dari semua lapisan staf yang memiliki pengetahuan dasar dari area spesifik yang terlibat (Lanida B.P, et al, 2019).

Salah satu pendekatan root cause analysis yang sering digunakan untuk menginvestigasi kesalahan atau kegagalan pada suatu kejadian atau peristiwa adalah five whys. Five Whys $(5 \mathrm{~W})$ merupakan metode yang dapat membantu menentukan hubungan sebab akibat pada permasalahan atau kegagalan yang terjadi. 5 whysmerupakan tahap analisis pemecahan masalah yang menyerupai pekerjaan detektif untuk menemukan hal baru dengan mengajukan pertanyaan "Mengapa?" berulang kali, sebanyak lima kali atau lebih dengan harapan dapat menemukan sumber suatu masalah, yaitu akarnya menggunakan $5 \mathrm{~W}$ adalah cara yang sederhana untuk mencoba memecahkan permasalahan tanpa investigasi yang sangat detail (Sondalini, 2015).

\section{e. Usulan Perbaikan dan Expected Future State Value Stream Mapping}

Perbaikan berdasarkan waste dominan dilakukan untuk memberikan usulan perbaikan yang akan dilakukan untuk mengurangi waste, tujuan melakukan perbaikan berdasarkan waste 
untuk meningkatkan PCE. Expected future state value stream mapping adalah ekspektasi atau harapan terhadap pemetaan value stream untuk kondisi mendatang setelah dilakukan perbaikan berdasarkan waste yang terjadi. Expected future state value stream mapping berguna dalam mengetahui perubahan dari eliminasi waste yang dilakukan pada proses pelayanan. Nilai harapan PCE pada Expected future state value stream mapping didapatkan dari simulasi menggunakan software ARENA.

\section{Pembahasan}

Aktivitas dalam proses pelayanan rawat jalan BPJS Poli Tulip beserta waktu yang harus dilalui pasien terlihat pada table 2. Aktivitas dibedakan menjadi tiga kategori yaitu value added (VA) activity, non value added (NVA) activity dan necessary non value added (NNVA) activity. Suatu aktivitas dikategorikan kedalam value added activity apabila memiliki nilai tambah terhadap proses pelayanan, aktivitas yang tidak memiliki nilai tambah dan tidak diperlukan maka termasuk kedalam kategori non value added activity, namun apabila suatu aktivitas tersebut tidak memberikan nilai tambah tetapi diperlukan maka termasuk kategori necessary non vaue added activity. Total VA activity $=1230$ detik. Total NVA activity $=4295$ detik. Total NNVA activity $=1761$ detik. Berdasarkan temuan ini maka didapatkan masih banyak kegiatan yang tidak bernilai tambah.

Tabel 2. Waktu Aktivitas Pasien dan Kategorinya

\begin{tabular}{|c|l|c|c|c|}
\hline \multirow{2}{*}{ No } & \multicolumn{2}{|c|}{ Tempat Aktivitas } & \multicolumn{3}{c|}{ Waktu (Detik) } \\
\cline { 3 - 5 } & & VA & NVA & NNVA \\
\hline 1 & Loket Pengambilan Tiket & 0 & 92 & 30 \\
\hline 2 & Loket Pembayaran BPJS & 0 & 3695 & 1485 \\
\hline 3 & Loket Pendaftaran Poli Rumah Sakit & 0 & 58 & 75 \\
\hline 4 & Pemeriksaan oleh Perawat & 300 & 0 & 2 \\
\hline 5 & Pemeriksaan dan konsultasi dengan dokter & 900 & 450 & 9 \\
\hline 6 & Loket Peletakan resep & 0 & 0 & 70 \\
\hline 7 & Loket Pengambilan obat & 30 & 10 & 90 \\
\hline \multicolumn{2}{r|}{ Total waktu (detik) } & 1230 & 4295 & 1761 \\
\hline
\end{tabular}

Hasil pembobotan kuesioner WRM yang telah disebarkan kepada para stake holder dapat dilihat pada Tabel 2. Arti Simbol yang digunakan adalah $\mathrm{F}$ melambangkan from, $\mathrm{T}$ melambangkan to, T melambangkan Unclear Communication, W melambangkan Delay, $\mathrm{M}$ melambangkan Unnecessary Movement, D melambangkan Duplication, O melambangkan Lost Oppurtinity To Retain or win Customers, I melambangkan Incorrect Inventory. 
Tabel 3. Pembobotan Jawaban Kuesioner WRM

\begin{tabular}{|l|l|l|l|l|l|l|}
\hline T & \multicolumn{2}{|c|}{ T } & \multicolumn{1}{|c|}{ W } & \multicolumn{2}{|c|}{ M } & \multicolumn{2}{|c|}{ D } & I & O \\
\hline T & A & O & I & U & U & E \\
\hline W & O & A & A & U & E & U \\
\hline M & I & A & A & O & E & E \\
\hline D & U & U & U & A & U & U \\
\hline I & U & E & U & O & A & U \\
\hline O & E & A & E & U & E & A \\
\hline
\end{tabular}

Untuk menyederhanakan setiap matrix pada Tabel 3 dikonversikan ke dalam setiap angka yang terlampir pada baris dengan acuan untuk $A=10, E=8, I=6, O=4, U=2$ dan $X=0$. Sesuai dengan yang dilakukan penelitian sebelumnya oleh (Rawabdeh, 2005). Dengan setiap acuan yang ada maka untuk melihat waste matrix value dapat dilihat pada Tabel 4.

Tabel 4. Waste Relationship Value

\begin{tabular}{|c|c|c|c|c|c|c|c|c|}
\hline $\mathbf{F}$ & $\mathbf{T}$ & W & $\mathbf{M}$ & D & I & $\mathbf{O}$ & Skor & $(\%)$ \\
\hline $\mathbf{T}$ & 10 & 4 & 6 & 2 & 2 & 8 & 32 & 15,38 \\
\hline $\mathbf{W}$ & 4 & 10 & 10 & 2 & 8 & 2 & 36 & 17,30 \\
\hline $\mathbf{M}$ & 6 & 10 & 10 & 4 & 8 & 8 & 46 & 22,11 \\
\hline D & 2 & 2 & 2 & 10 & 2 & 2 & 20 & 9,64 \\
\hline I & 2 & 8 & 2 & 4 & 10 & 2 & 28 & 13,46 \\
\hline $\mathbf{O}$ & 8 & 10 & 8 & 2 & 8 & 10 & 46 & 22,11 \\
\hline Skor & 32 & 44 & 38 & 24 & 38 & 32 & 208 & 100 \\
\hline$(\%)$ & 15,38 & 21,15 & $\begin{array}{l}18,2 \\
6\end{array}$ & 11,57 & $\begin{array}{l}18,2 \\
6\end{array}$ & $\begin{array}{l}15,3 \\
8\end{array}$ & 100 & \\
\hline
\end{tabular}

Tabel 4. Waste relationship value memiliki baris dan kolom. Baris menunjukkan besar pengaruh suatu waste terhadap terjadinya waste lainnya, sedangkan kolom menunjukkan besar terjadinya suatu waste akibat adanya waste tertentu. Dari hasil pengolahan data menggunakan waste relationship matrix, dapat diketahui bahwa pengaruh timbulnya waste lain akibat unclear 
communication sebesar $15,38 \%$, pengaruh timbulnya waste lain akibat delay sebesar $17,30 \%$, pengaruh timbulnya waste lain akibat unecessary movement sebesar $22,11 \%$, pengaruh timbulnya waste lain akibat duplication sebesar $9,64 \%$ dan pengaruh timbulnya waste lain akibat incorrect inventory sebesar $13,46 \%$ serta pengaruh timbulnya waste lain akibat lost opportunity to retain or win customers sebesar $22,11 \%$. unnecessary movement dan lost oppurtunity to retain or win customers merupakan waste paling tinggi persentasenya menyebabkan timbulnya waste lain dan waste yang ditimbulkan pesentasenya paling tinggi adalah delay yaitu sebesar $21,15 \%$.

Tools interrelationship diagram dan 5 whys digunakan untuk mengetahui akar penyebab permasalahan yang terjadi terkait waktu tunggu. Ditemukan 2 faktor permasalahan waktu tunggu pada BPJS Poli Tulip, yaitu factor individual dan manajerial.

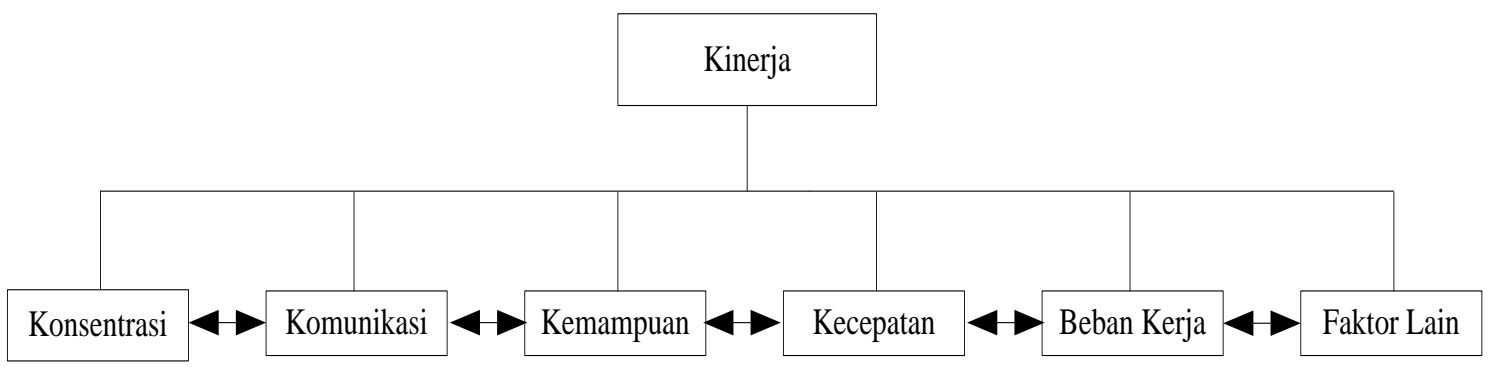

Gambar 3 Kerangka Pemikiran Yang Mempengaruhi Rawat Jalan Pasien BPJS

Berdasarkan Gambar 4, penyebab permasalahan waktu tunggu pasien $\geq 60$ menit berdasarkan faktor utama individual adalah karyawan terlambat, ini dapat terjadi pada loket pendaftaran BPJS, petugas yang terlambat dapat menyebabkan antrian panjang karena pasien yang sudah memiliki nomor antrian akan menunpuk untuk dilayani dan pasien akan mengantri untuk melakukan proses selanjutnya dan faktor lain individual terkait beban kerja, kecepatan dan ketepatan dalam bekerja.

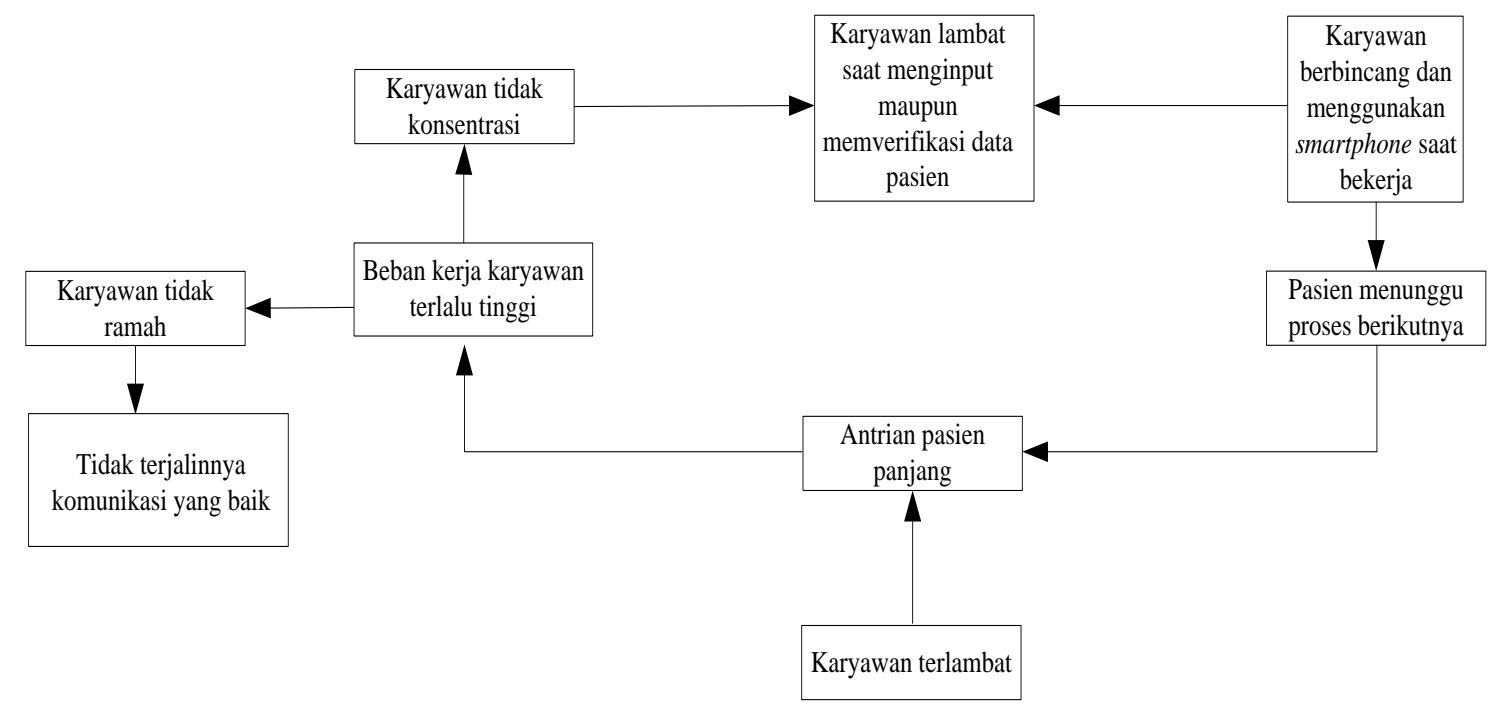

Gambar 4. Interrelationship Diagram Antar Masalah Faktor Individual 


\section{Wresni Anggraini, Anifah Naswan Ilhamda Putri}

Berdasarkan Gambar 5, Faktor utama manajerial ini biasanya terjadi saat pasien BPJS yang diterima melebihi dari kesanggupan petugas karena rumah sakit ini melayani pasien rawat jalan BPJS dan umum. Pasien yang sudah memiliki nomor antrian tetap dilayani sampai pasien pulang namun pasien akan menunggu $\geq 60$ menit karena petugas akan melaukan istirahat pada jam 12.00-13.00 WIB dan jam 16.00-17.00 WIB. Pasien BPJS tetap bisa melakukan pengambilan nomor antrian saat loket BPJS masih buka, apabila rumah sakit tetap menerima pasien lewat jam 11.00 dan jumlah pasien sudah melebihi dari kesanggupan petugas maka untuk mendapatkan pelayanan pasien akan melewati 2 kali waktu istirahat ini disebabkan karena pasien sudah menumpuk untuk dilayani dan pasien akan dilayani oleh dokter berbeda karena dokter yang melayani dalam 1 hari ada 2 orang dokter dan faktor lain yang menyebabkan waktu tunggu adalah gangguan jaringan dan dokter secara mendadak harus melakukan tindakan emergency.

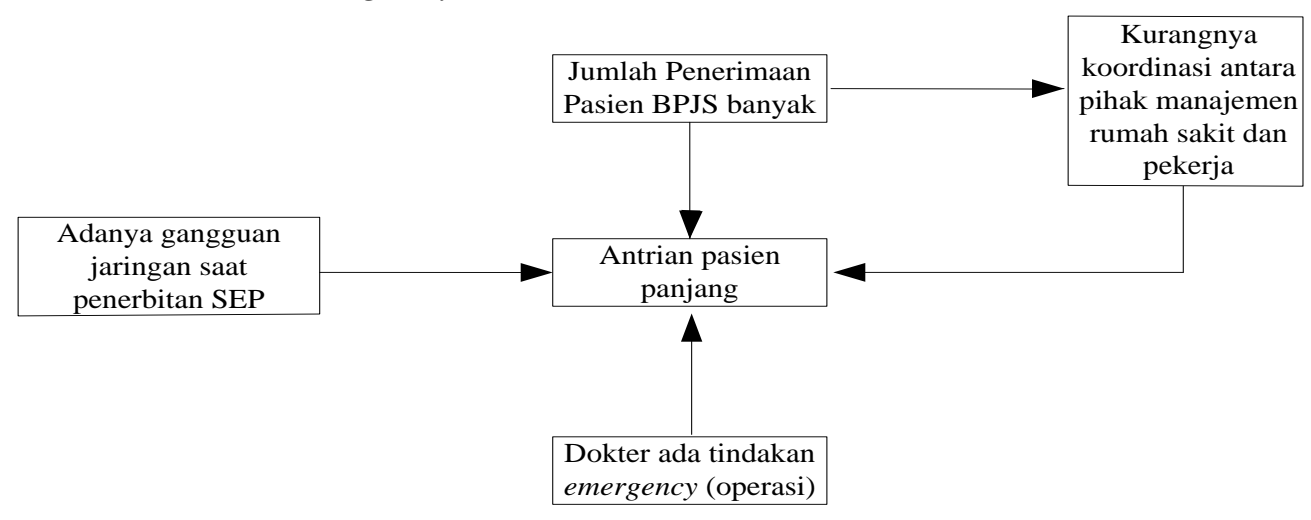

Gambar 5. Interrelationship Diagram Antar Masalah Faktor Manajerial

Berdasarkan hasil kuesioner 5 Whys Question yang disebarkan kepada value stakeholder untuk mengetahui apa akar penyebab pemborosan yang paling dominan yaitu waste delay, didapatkan hasil seperti terlihat pada table 5.

Tabel 5. 5-Whys Waste Delay

\begin{tabular}{|c|c|}
\hline \multicolumn{2}{|c|}{5 whys waste delay } \\
\hline Why Ouestions & Answer \\
\hline $\begin{array}{l}\text { Mengapa waste delay terjadi pada proses } \\
\text { pelayanan pasien rawat jalan BPJS poli } \\
\text { tulip? }\end{array}$ & $\begin{array}{l}\text { Karena terjadi miss communication antara petugas, } \\
\text { perawat dan dokter. }\end{array}$ \\
\hline Mengapa terjadi miss communication? & $\begin{array}{l}\text { Miss communication terjadi karena kurangnya } \\
\text { koordinasi antara petugas, perawat dan dokter. }\end{array}$ \\
\hline Mengapa kurangnya koordinasi? & $\begin{array}{l}\text { Karena saat bekerja petugas, perawat dan dokter sibuk } \\
\text { dengan tugas masing-masing dan tidak adanya sistem } \\
\text { yang menghubungkan petugas, perawat dan dokter. }\end{array}$ \\
\hline $\begin{array}{l}\text { Mengapa tidak adanya sistem yang } \\
\text { menghubungkan sesama pekerja? }\end{array}$ & $\begin{array}{l}\text { Karena pihak rumah sakit belum mengembangkan } \\
\text { sistem informasi berbasis komputer (Computer Based } \\
\text { Hospital Information System) }\end{array}$ \\
\hline $\begin{array}{l}\text { Mengapa pihak rumah sakit belum } \\
\text { mengembangkan sistem informasi } \\
\text { berbasis computer? }\end{array}$ & $\begin{array}{l}\text { Karena pihak rumah sakit fokus utamanya adalah } \\
\text { pengembangan fasilitas dan kesehatan pasien. }\end{array}$ \\
\hline
\end{tabular}


Berdasarkan akar permasalahan yang terjadi, maka diusulkan beberapa Langkah usulan guna memperbaiki layanan dan menghilangkan waste yang terjadi pada proses pelayanan rawat jalan pasien BPJS Poli Tulip dapat dilihat pada Tabel 6.

Tabel 6. Usulan Untuk menghilangkan Waste

\begin{tabular}{|c|c|}
\hline Waste & Usulan Untuk Mengilangkan Waste \\
\hline Duplication & $\begin{array}{l}\text { Petugas harus meingkatkan kecepatan dan ketepatan dalam } \\
\text { bekerja }\end{array}$ \\
\hline Delay & $\begin{array}{l}\text { Pihak rumah sakit perlu merealisasikan sistem informasi untuk } \\
\text { rumah sakit yang berkesinambungan agar tercapainya komunikasi } \\
\text { dan informasi antar petugas, perawat dan dokter }\end{array}$ \\
\hline $\begin{array}{l}\text { Unnecessary } \\
\text { Movement }\end{array}$ & $\begin{array}{l}\text { 1. Perlunya penataan lingkungan kerja petugas penerbitan SEP } \\
\text { 2. SOP dalam penyambungan pasien pendaftaran BPJS dapat } \\
\text { diperbaiki karena aktivitas yang dilakukan tersebut berlebihan }\end{array}$ \\
\hline $\begin{array}{l}\text { Unclear } \\
\text { Communication }\end{array}$ & $\begin{array}{l}\text { Petugas pengambilan obat harus menjelaskan dengan bahasa yang } \\
\text { mudah dipahami pasien dalam menjelaskan penggunaan obat }\end{array}$ \\
\hline $\begin{array}{l}\text { Lost opportunity to } \\
\text { retain or win } \\
\text { customers }\end{array}$ & $\begin{array}{l}\text { 1. Pekerja harus profesional dalam bekerja karena harus } \\
\text { menciptakan suasana yang nyaman bagi pasien dan wajib bagi } \\
\text { pekerja menerapkan } 5 \mathrm{~S} \text { (senyum, sapa, salam, sopan dan santun) } \\
\text { 2. Pihak rumah sakit dan petugas tidak boleh membedakan } \\
\text { pelayanan maupun fasilitas yang diberikan kepada pasien BPJS }\end{array}$ \\
\hline Incorrect Inventory & $\begin{array}{l}\text { 1. Pihak rumah sakit harus tegas dengan jam pengambilan nomor } \\
\text { antrian } \\
\text { 2. Menatapkan target pasien yang dilayani dalam } 1 \text { kali siklus } \\
\text { pelayanan }\end{array}$ \\
\hline
\end{tabular}

Usulan perbaikan yang direkomendasikan kemudian disimulasikan menggunakan simulasi ARENA dan kemudian diperoleh expected Future Value Stream Mapping seperti pada gambar 8, dan diperoleh nilai Expected PCE sebesar 36,18\%. 


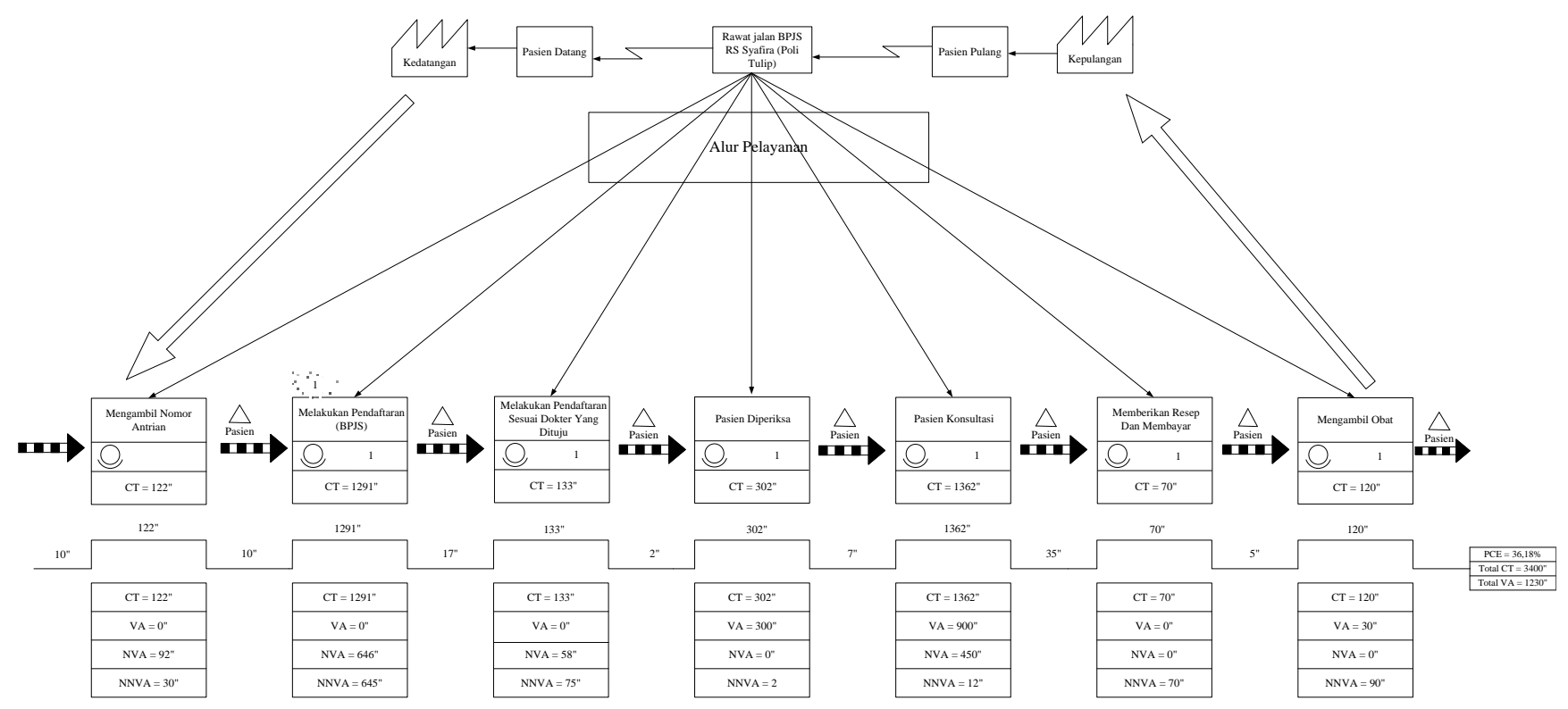

Gambar 6. Future State Value Stream Mapping Proses Pelayanan Rawat Jalan BPJS Poli Tulip

\section{Kesimpulan}

1. Aktivitas dalam proses pelayanan rawat jalan BPJS Poli Tulip meliputi proses: pengambilan tiket/no antrian, pendaftaran BPJS, pendaftaraan Rumah Sakit, proses pemeriksanaan perawat, proses pemeriksaan dan konsultasi dengan dokter, peletakan resep dan proses pengambilan obat. Total VA activity $=1230$ detik. Total NVA activity $=4305$ detik. Total NNVA activity = 1761 detik.

2. Akar penyebab masalah dari waste yang terjadi di lini pelayanan Poli Tulip Rumah Sakit $\mathrm{X}$ Pekanbaru bersumber dari faktor individual dan manajerial, seperti digambarkan pada gambar 6 dan 7.

3. Usulan perbaikan pelayanan untuk mengurangi waktu tunggu pelayanan pasien disampaikan pada table 5 dan berdasarkan simulasi yang dilakukan terhadap usulan yang diberikan, diperoleh expected Process Cycle Efficiency pada lini layanan Poli Tulip sebesar $36,18 \%$, meningkat $19,33 \%$ dari kondisi awal.

\section{Daftar Pustaka}

Ahmad H.S, Rochmah T.N and Setianto B. (2020) "Implementation of lean management to reduce waiting time for drugs in Islamic Hospital, EurAsian Journal of BioSciences Eurasia J Biosci 14, 2693-2696

Anggraini, W. (2020) "Lean Services Untuk Perbaikan Pelayanan Administrasi Akademik di Universitas", Jurnal Teknik Industri Vol. 6, No. 1, 2020, 21-26

Gaspers.V \& Fontana.A. (2011) "Lean Six sigma for manufacturing and Service Industries". PT Gramedia Pustaka Utama, Jakarta

Graban, M. (2009) "Lean Hospital : Improving Quality, Patient Safety, and Employee Satisfaction”. New York: CRC Press. 
Kovacevic M, Jovicic M, Djapan M, and Zivanovic-Macuzic I., (2016) "Lean thinking in healthcare: Review of implementation results," International Journal for Quality Research, vol. 10, no. 1, 219-230, 2

Lanida B.P, Yustiawan T, and Dzykryanka S.M, (2019) "Root Cause Analysis on Hospital Standards and Joint Commission International Standards: a Comparative Study," Jurnal Administrasi Kesehatan Indonesia., vol. 7, no. 1, 18-24.

Rawabdeh, I. A. (2005) "A Model for the Assessment of Waste in Job Shop Environments", International Journal of Operations \& Production Management, Vol. 25, pp. 800-822.

Rochman, Fitrah M R, Sugiono dan Efranto R Y (2014) "Penerapan Lean Manufacturing Menggunakan WRM, WAQ dan VALSAT Untuk Mengurangi Waste pada Proses Finishing (Studi Kasus di PT. Temprina Media Grafika Nganjuk)”. Jurnal Teknik Industri Vol 2, No. 4. Universitas Brawijaya. Malang.

Rooney, James J. dan Lee N. Vanden Heuvel. (2014) "Root Cause Analysis for Beginners". EBook Quality Basics. 2014. https://www.env.nm.gov. Diakses pada tanggal 2 Februari 2017.

Setyaningsih, I (2013) “Analisis kualitas pelayanan rumah sakit terhadap pasien menggunakan pendekatan lean servperf (Lean Service dan Service Performance) (Studi kasus rumah sakit X)", Jurnal Spektrum Industri Vol. 11 No. 2, 133- 148

Sondalini M. (2015) "Understanding How to Use The 5-Whys for Root Cause Analysis". Ebook Lifetime Reliability.. http://www.lifetime-reliability.com. Diakses pada tanggal 22 Januari 2017.

Syahri, R. F. et al., (2017) "Analisis Waste Dengan Value Stream Mapping Pada Pekerjaan Kolom Gedung Bertingkat", Jurnal Karya Teknik Sipil Vol. 6, 192-200 